Original Research

\title{
Preparation of Spin-Coated Poly(vinyl alcohol)/ chitosan/ Gold Nanoparticles Composite and Its Potential for Colorimetric Detection of Cyanide in Water
}

\author{
Marco Laurence M. Budlayan', Jeanne Phyre L. Oracion², Lyka B. De La Rosa ${ }^{2}$, \\ Mikee Joy D. Rodriguez ${ }^{2}$, Jonathan N. Patricio³, Ser John Lynon P. Perez ${ }^{3}$, \\ Susan D. Arco ${ }^{3}$, Jonathan P. Manigo ${ }^{4,5}$, Eleanor S. Austria ${ }^{6}$, Arnold C. Alguno ${ }^{7}$, \\ Custer C. Deocaris ${ }^{8}$, Rey Y. Capangpangan ${ }^{9 *}$
}

${ }^{1}$ Physics Department, Ateneo de Manila University, Quezon City 1101, Philippines ${ }^{2}$ Materials Science and Polymer Chemistry Laboratory, Caraga State University, Butuan City 8600, Philippines ${ }^{3}$ Synthetic Organic Chemistry Research Laboratory, University of the Philippines Diliman, Quezon City 1101, Philippines

${ }^{4}$ Physics Department, Caraga State University, Butuan City 8600, Philippines ${ }^{5}$ Center for Nanoscience and Technology for Research and Entrepreneurship, Caraga State University, Butuan City 8600, Philippines

${ }^{6}$ Biology Department, Adamson University, 900 San Marcelino St., Ermita, Manila 1000, Philippines ${ }^{7}$ Physics Department, Mindanao State University-Iligan Institute of Technology, Iligan City 9200, Philippines

${ }^{8}$ Biomedical Research Section, Philippine Nuclear Research Institute, Quezon City 1101, Philippines

${ }^{9}$ Department of Physical Sciences and Mathematics, College of Science and Environment, Mindanao State University - Naawan Campus, 9023, Misamis Oriental, Philippines

Received: 3 May 2021

Accepted: 16 July 2021

\begin{abstract}
The rampant use of cyanide in mining activities has posed a substantial hazard to aquatic ecosystems and human health. Herein, a composite film of poly(vinyl alcohol)/chitosan (PVA/CS) with gold nanoparticles was synthesized as a potential colorimetric sensor for cyanide ions detection in water. The utilized AuNPs with a mean diameter of $14.32 \pm 3.49 \mathrm{~nm}$ were synthesized by chemical reduction using polyethyleneimine. Ultraviolet-visible spectroscopy revealed the characteristic peak of AuNPs at around $530 \mathrm{~nm}$ in the spectrum of PVA/CS/AuNP film, while SEM microscopy revealed the integration AuNPs across the polymer substrate. A color change from red to colorless was observed on the composite film after the addition of water samples with cyanide ions with a visual detection limit between 0.1-1 ppm. The sensor also exhibited good selectivity towards cyanide against the tested water samples containing
\end{abstract}

e-mail: rey.capangpangan@msunaawan.edu.ph 
various metal ions. This study reveals the potential of the fabricated PVA/CS/AuNP composite film as a simple, affordable, and environmentally benign material for on-site detection of cyanide in water and other related application.

Keywords: cyanide, polyvinyl alcohol, chitosan, gold nanoparticle, composite, colorimetric sensor, water contamination monitoring

\section{Introduction}

The cyanide ion $\left(\mathrm{CN}^{-}\right)$is a toxic environmental pollutant naturally present in the environment through natural phenomena such as volcanic eruptions and industrial activities such as chemical processing and mining [1]. Accordingly, $\mathrm{CN}^{-}$targets the biological system, particularly the cardiovascular and nervous systems [2] of an organism especially making it extremely harmful when ingested, particularly at high concentration. The active monitoring of $\mathrm{CN}^{-}$is therefore important for human and environmental protection. Several methods have been developed to detect $\mathrm{CN}^{-}$in water accurately, but these methods are mostly challenged by technical complexities, high cost, and non-portability. Standard techniques such as spectroscopy, gas chromatography, titrimetry, amperometry, and electrochemistry all entailed complicated instrumentation, special training, and tedious sample preparation [3, 4]. This led researchers to explore other suitable materials and analytical platforms for rapid and reliable detection of $\mathrm{CN}^{-}[5,6]$.

To date, nanomaterials present an exciting alternative for sensing applications. Nanoparticles (NPs) of noble metals such as gold and silver are particularly attracting wide attention due to their unique electronic property such as the localized surface plasmon resonance (LSPR). The high surface-area-tovolume ratio and surface energy also give nanoparticles an outstanding and distinctive behavior relative to their bulk counterparts $[7,8]$. These materials have high extinction coefficients in the visible region [9], giving them the potential for spectroscopic (i.e., UV-Vis and Raman spectroscopy) and colorimetric (i.e., naked eye) sensing [10, 11], among many other applications. Recently, solid-phase sensors are also developed wherein the NPs are usually immobilized onto various solid supports such as paper, glass, metal sheets, and polymer film $[12,13]$. This step protects the nanoparticles against aggregation and surface oxidation, thus promoting a longer shelf life and enhancing its usability. In particular, polymer films were sought to offer a stable platform for nanoparticle integration [14, 15]. The mechanical strength, chemical stability, and compatibility of polymers and their composites with nanoparticles were taken advantage of to improve nanoparticles' portability and responsiveness, especially for sensing applications [16]. For instance, chitosan (CS), a naturally polycationic polymer derived from chitin by deacetylation [17], is widely used in composite with various nanoparticles due to its biodegradability, biocompatibility, and abundance with hydrogen bonds can that interact and with various nanomaterials $[18$, 19]. Several works reported the promising application of CS and metallic nanoparticle composites in tissue engineering, drug delivery, and gene therapy [20, 21]. Despite these desirable properties, chitosan, like other natural polymers, possesses poor mechanical properties $[22,23]$. To overcome this drawback, chitosan blending with other polymers is being done to produce polymer composites with enhanced mechanical and chemical properties. Poly(vinyl alcohol) (PVA), in particular, is a hydrophilic polymer that is widely used in film preparation due to its biodegradability and low toxicity [24]. Its strong intermolecular attraction with CS through hydrogen bonding and the good wetting property is also advantageous, especially for sensing applications in water media $[25,26]$. Moreover, the combination of CS and PVA has been reported to have good mechanical and chemical stability. It is widely studied and used for packaging, dye adsorption, biomedicine, and membrane filtration [27].

In this study, PVA, chitosan, and gold nanoparticles (AuNPs) were used to produce a PVA/chitosan/gold nanoparticles (PVA/CS/AuNP) composite via spin coating technique. The PVA/CS/AuNP composite film was found to have a good plasmonic property. The fabricated composite film exhibited a promising potential for an easy, cost-effective, and on-site monitoring of $\mathrm{CN}^{-}$ions in water through visual colorimetric detection.

\section{Experimental}

\section{Materials Collection}

Commercially purchased low molecular weight (MW) chitosan (50,000-190,000 MW, Sigma-Aldrich), PEI (branched, 25,000 MW., Scharlau), gold(III) chloride trihydrate $\left(\mathrm{HAuCl}_{4} \cdot 3 \mathrm{H}_{2} \mathrm{O}, \geq 49.0 \% \mathrm{Au}\right.$ basis, Sigma-Aldrich), PVA (99+\% hydrolyzed, 85,000-124,000 M.W. Sigma-Aldrich), glacial acetic acid $(>99.7 \%$, Sigma-Aldrich) were primarily used to synthesize PVA/CS and AuNPs. Analytical grade metal salts including aluminum nitrate, arsenic oxide, cadmium chloride, calcium nitrate (all from Univar), and lead nitrate, magnesium chloride, manganese chloride, and nickel sulfate (all from Scharlau) were also used. Potassium cyanide (KCN, Univar) was used as a cyanide precursor in the sensing experiment. Potassium chloride (KCl, Sigma-Aldrich) was also used. 
Deionized water was used in preparing all the solutions needed in the study.

\section{Synthesis of Gold Nanoparticles}

The synthesis of colloidal AuNPs used in this study was done using a typical chemical reduction with PEI as the primary reducing and stabilizing agent. Briefly, $1 \mathrm{~mL}$ of $0.025 \mathrm{M} \mathrm{HAuCl}_{4} \cdot 3 \mathrm{H}_{2} \mathrm{O}$ was mixed with $10 \mathrm{mM}$ of PEI. The $\mathrm{pH}$ of the mixture was adjusted to 7 under vigorous stirring. The mixture was kept to react for three (3) days at ambient conditions until a stable, wine red-colored solution was obtained.

\section{Preparation and Spin-Coating of PVA/Chitosan/AuNPs}

The polymeric blend of PVA and CS was prepared by co-dissolving PVA and CS in acetic acid. In detail, $3.0 \mathrm{~g}$ of PVA/CS $(9: 1 \mathrm{w} / \mathrm{w})$ solution was dissolved in $2 \%$ acetic acid at $80-90^{\circ} \mathrm{C}$ for $60 \mathrm{~min}$ with vigorous stirring. After cooling down, approximately $10 \mathrm{~mL}$ of the polymer blend was added with $2 \mathrm{~mL}$ PEIreduced AuNPs and was stirred using a vortex mixer for 2 rounds ( $1 \mathrm{~min} /$ round). This was subjected to spin coating deposition using a spin coater (Glichn T108 spin coater) with a speed of $200 \mathrm{rpm}$ (around 30 seconds deposition time). To ensure evaporation of the residual solvent, the spin-coated film was dried at ambient temperature for at least $72 \mathrm{~h}$. The film is stored in the dry box for further use and characterization.

\section{Application PVA/Chitosan/AuNPs Composite for Cyanide Detection in Water}

To investigate the potential applicability of the fabricated PVA/Chitosan/AuNP composite film for cyanide detection, samples were cut into $5 \mathrm{~mm} \times 5 \mathrm{~mm}$ strips and were placed on a spot plate. Two (2) drops (about $25 \mu \mathrm{L}$ ) of standard cyanide solution of varying concentrations ( 0.01 to $100 \mathrm{ppm})$ were dropped on the prepared composite film. The changes in the color of the samples were observed and noted for up to 15 minutes. Similarly, the film was tested with water samples containing other metal ions $\left(\mathrm{Cd}^{2+}, \mathrm{As}^{2+}, \mathrm{Al}^{2+}\right.$, $\mathrm{Mn}^{2+}, \mathrm{Ni}^{2+}, \mathrm{Pb}^{2+}$, and $\mathrm{Mg}^{2+}$ to assess the selectivity of the fabricated colorimetric sensor. $\mathrm{KCl}$ was also used to test the colorimetric response of the film with $\mathrm{K}^{+}$ions.

\section{Characterization Techniques}

UV-Vis absorbance measurements were taken using Perkin Elmer Ensight ${ }^{\mathrm{TM}}$ multimode plate reader to monitor the formation of AuNPs and their incorporation into the PVA/Chitosan composite blend. A similar technique was employed to monitor the change in the samples' optical absorbance in the colorimetric detection of cyanide in water. Fourier-transform infrared radiation (FT-IR, Perkin Elmer Spectrum 2 Spectrometer) spectroscopy was conducted to determine the functional groups observed in the samples. Scanning electron microscopy (SEM, FEI Quanta 400F Oxford) and transmission electron microscopy (TEM, JEOL JEM1010) were employed to investigate the samples' morphological profile.

\section{Results and Discussion}

\section{Formation of PEI-Functionalized AgNPs and Characterization of PVA/CS/AuNP Composite}

Fig. 1 shows the schematic diagram of the experimental setup used in the study. The polymer composite film strip with the integrated AuNPs was obtained after the spin coating process.

The successful formation of AuNPs in the presence of PEI as a reducing and stabilizing agent was visually observed by the lustrous wine-red appearance of AuNPs suspension in water. This can be supported by the appearance of a peak at around $525 \mathrm{~nm}$ on the UV-vis absorbance spectrum of PEI-reduced AuNPs shown in Fig. 2a). This absorbance peak profile is commonly associated with the SPR of spherical gold nanoparticles that is generally reported in previous literature [28]. The corresponding TEM result (Fig. 2b) revealed the presence of spherical AuNPs with particle sizes ranging from 7.69 to $22.72 \mathrm{~nm}$. In general, the mean diameter of the AuNPs was estimated to around $14.32 \pm 3.49 \mathrm{~nm}$, as shown in the size histogram (Fig. 2b inset).

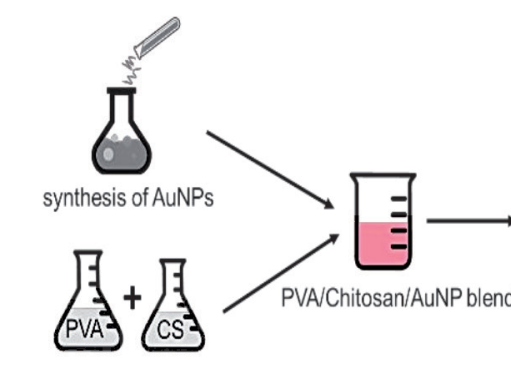

preparation of PVA/Chitosan blend

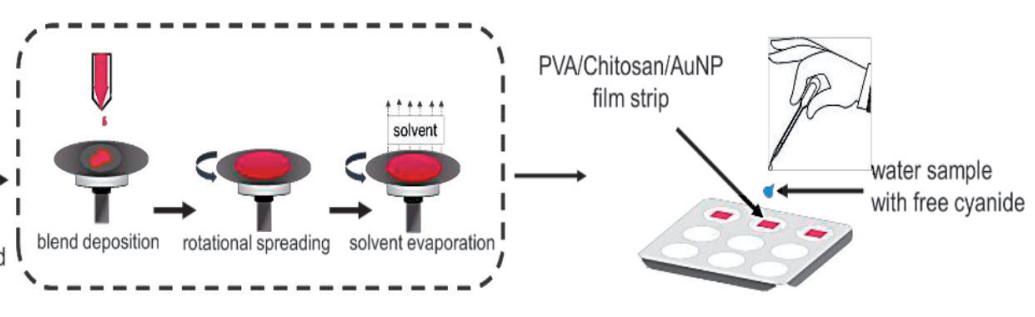

spin coating technique

Fig. 1. Schematic draft of the experimental workflow of the study. 

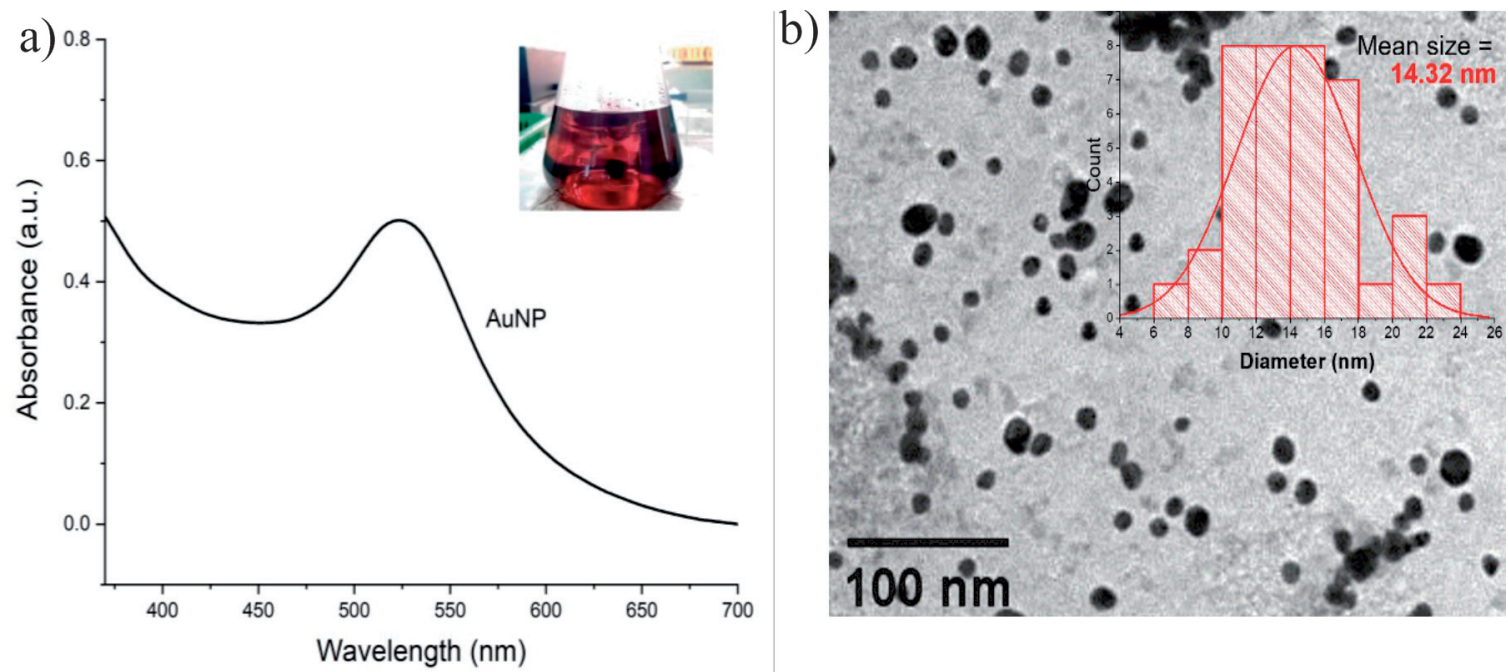

Fig. 2. a) UV-Vis Spectrum of the AuNPs (Inset is the Photograph of the Sample) and b) TEM Image and Size Histogram of AuNPs.

The prepared AuNPs were added to the PVA/CS polymer blend to produce PVA/CS/AuNP composite. The UV-Vis spectra and images of the PVA/CS polymer and PVA/CS/AuNP composites are shown in Fig. 2a). After the spin-coating process, a consistently clear and nearly transparent appearance of the resulting PVA/CS composite was observed. At the same time, a reddish color was apparent in the PVA/CS/AuNP composite film. This notable difference in color is attributed to the successful integration of the plasmonic AuNPs into the polymer blend. This observation was validated by the appearance of a peak at around $530 \mathrm{~nm}$ in the UV-vis spectrum of PVA/CS/AuNP. This peak corresponding to the SPR of AuNPs is certainly absent in the UV-Vis spectrum of the pure PVA/CS composite material. The uniform distribution of the AuNPs was also manifested through the red color's consistency on the spin-coated PVA/CS/AuNP. However, the presence of air bubbles was observed in the samples that may be due to the pockets of air trapped in the polymer mixture during the spin-coating process since the deposition was not conducted under a vacuum. Nonetheless, qualitative inspection suggests that the flexibility and durability of the polymeric film before and after the addition of AuNPs are comparable.

The morphological profile of the samples was viewed using SEM micrographs as presented in Fig. 3(b-c). In the micro image of PVA/CS, a smooth surface
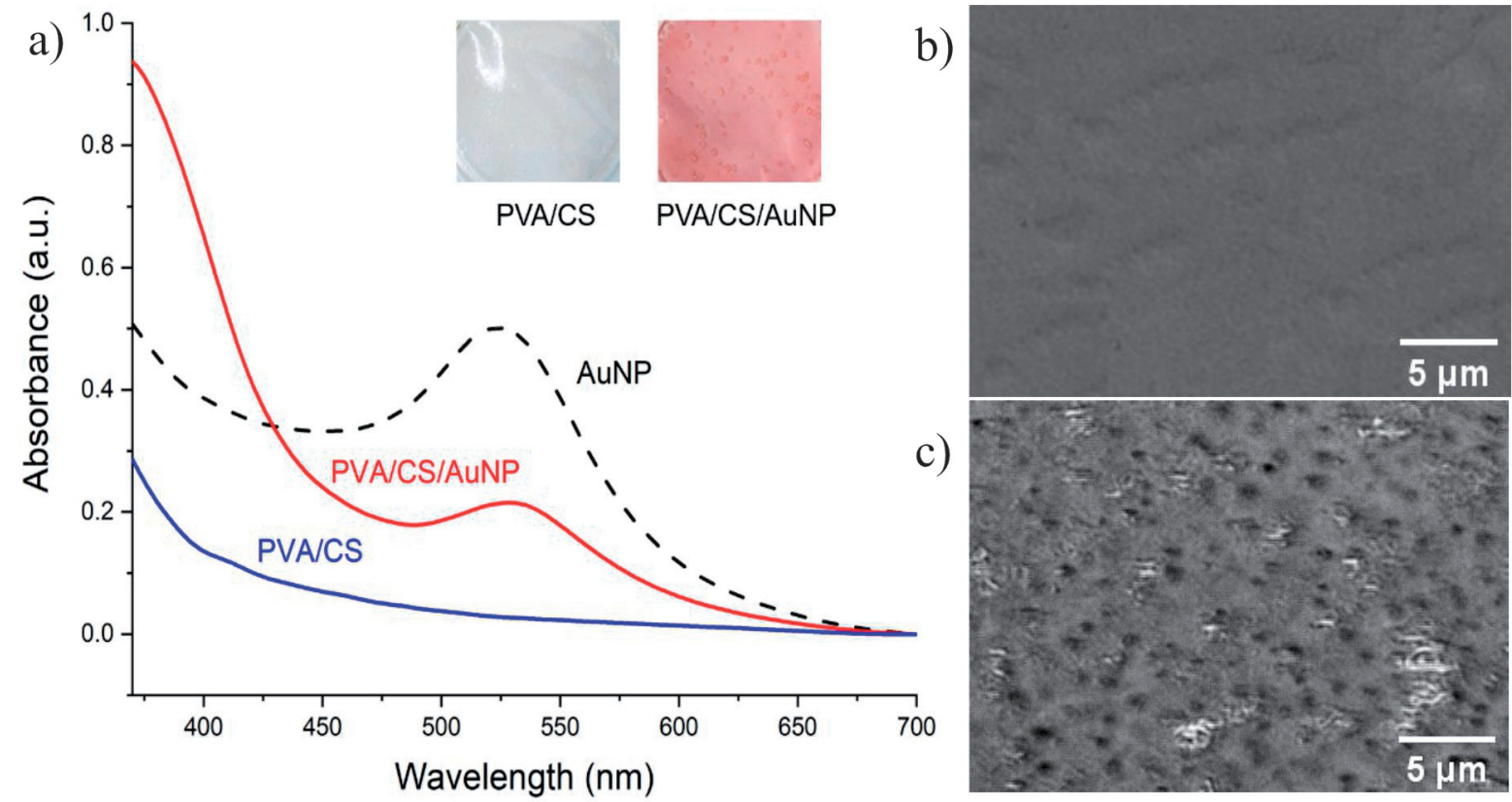

Fig. 3. a) UV-Vis Spectra of the PVA/CS and PVA/CS/AuNP (inset is the Magnified Photograph of the Samples) and SEM Image of the b) PVA/CS and c) PVA/CS/AuNP 
was observed with the occasional presence of bumps that can be ascribed to the air pockets as previously mentioned. After integrating the AuNPs, an apparent coarseness on the surface of the PVA/CS/AuNP was observed. This change in the surface profile of the PVA/CS/AuNP might be due to the presence of dense AuNP trapped on the polymer matrices. As can be seen, the observed dark spots and course surface is consistent across the sample suggesting the immobilization of the AuNPs on the polymer composite.

The FT-IR spectra of the obtained composite and its respective starting materials (PVA and chitosan) were obtained to investigate the samples' compositional properties (Fig. 4). A broad transmittance band at around 3500-3000 $\mathrm{cm}^{-1}$ was commonly observed in CS, PVA, PVA/CS, and PVA/CS/AuNP films. This was attributed to $-\mathrm{OH}$ stretching adsorbed water on the samples, while the peaks at $3000-2800 \mathrm{~cm}^{-1}$ can be linked to $\mathrm{C}-\mathrm{H}$ stretching vibration commonly observed in CS and PVA [29-30]. These bands overlapped with the very weak bands at around $3200-3100 \mathrm{~cm}^{-1}$ assigned to the overtone of the $-\mathrm{NH}_{2}$ vibration of the amine groups present in the CS. Bands at around $1650 \mathrm{~cm}^{-1}, 1558 \mathrm{~cm}^{-1}$, $1426 \mathrm{~cm}^{-1}, 1370 \mathrm{~cm}^{-1}, 1162 \mathrm{~cm}^{-1}$, and $1069 \mathrm{~cm}^{-1}$ were also observed in the spectrum of $\mathrm{CS}$, signifying the presence of $\mathrm{C}=\mathrm{O}, \mathrm{N}-\mathrm{H}, \mathrm{C}-\mathrm{H}, \mathrm{C}-\mathrm{C}, \mathrm{C}-\mathrm{N}$, and $\mathrm{C}-\mathrm{O}$ bonds [29-31]. Meanwhile, transmittance bands at around $1414 \mathrm{~cm}^{-1}$, $1144 \mathrm{~cm}^{-1}$, and $839 \mathrm{~cm}^{-1}$ were observed in the spectrum of PVA. These bands are associated with the $\mathrm{C}-\mathrm{H}, \mathrm{C}-\mathrm{O}$, and $\mathrm{C}-\mathrm{C}$ bonds present in the PVA [30]. Interestingly, all the bands observed in the spectrum of CS and PVA were present in the PVA/CS spectrum suggesting the successful blending of CS and PVA precursors. Similar bands but with more defined intensities were also observed in the spectrum of PVA/CS/AuNP composite film, indicating the strong vibrations of the preserved functional groups of the PVA/CS blend with the AuNPs.

\section{Colorimetric Detection of Free Cyanide in Water}

The application of the PVA/CS/AuNP composite as a colorimetric sensor for cyanide ions in water was investigated. Although the potential of AuNPs for cyanide detection has already been reported in previous literature, most of the investigations are focused on the use of AuNPs in its colloidal or liquid phase [3336]. Hence, investigating the potential of immobilized AuNPs in a biodegradable polymer solid substrate such as PVA/CS for similar applications could advance the portability and stability of AuNP-based colorimetric sensors. Cyanide-contaminated water samples were dropped on the PVA/CS/AuNP, and the color change was observed minutes after the addition. Interestingly, the color of the PVA/CS/AuNP changed from red to colorless in the presence of a water sample with a high cyanide concentration ( $80 \mathrm{ppm})$. In comparison, no color change was observed after the addition of a water sample with no cyanide content $(0 \mathrm{ppm})$. The color change intensity was found to vary depending on the concentration of cyanide in the water samples, producing a color gradient as displayed in Fig. 5c). This visual observation was validated by the decreasing intensity of the absorbance peak at around $530 \mathrm{~nm}$ of the PVA/CS/AuNP with increasing $\mathrm{CN}^{-}$concentration (Fig. 5a-b). It is worthy of mentioning that the color

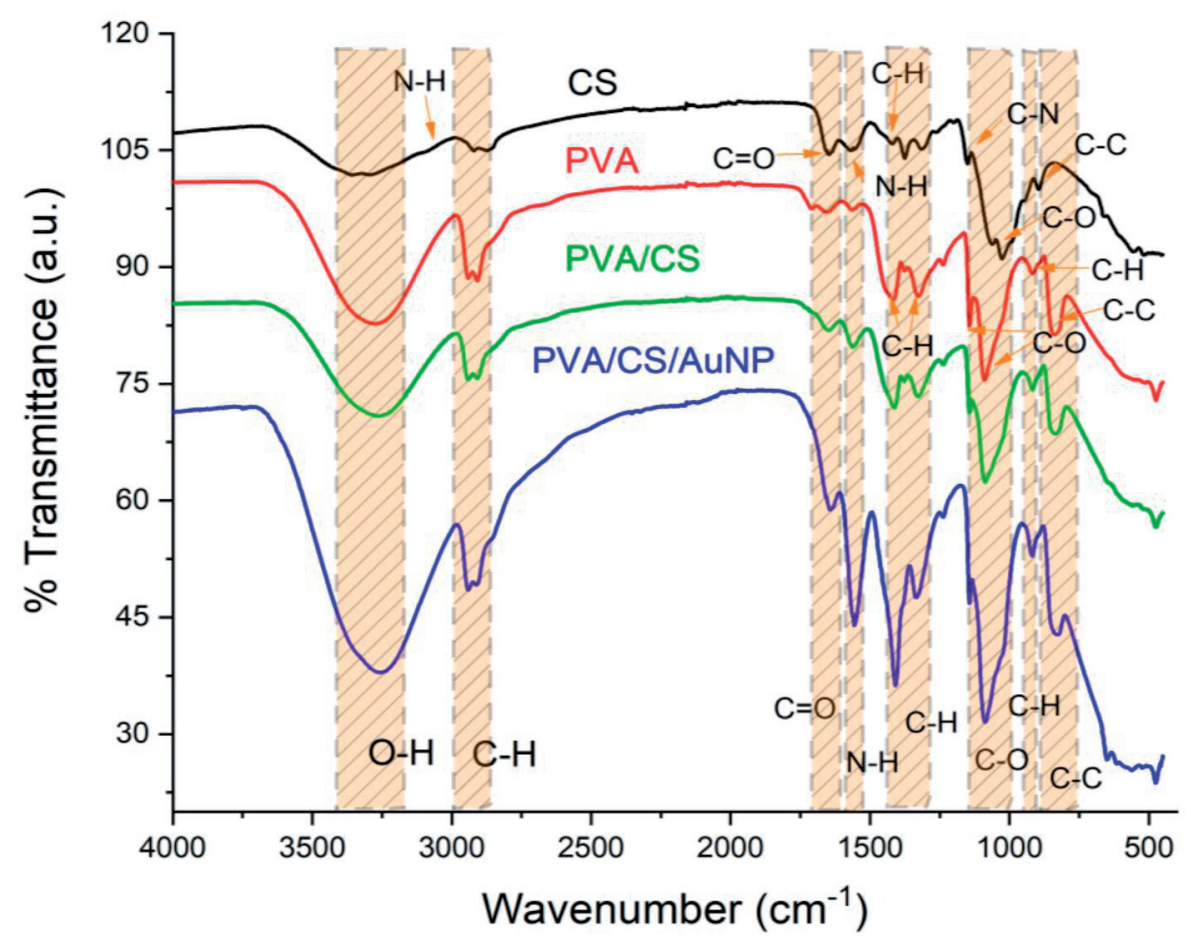

Fig 4. FT-IR spectra of chitosan, PVA, PVA/CS, and PVA/CS/AuNP. 

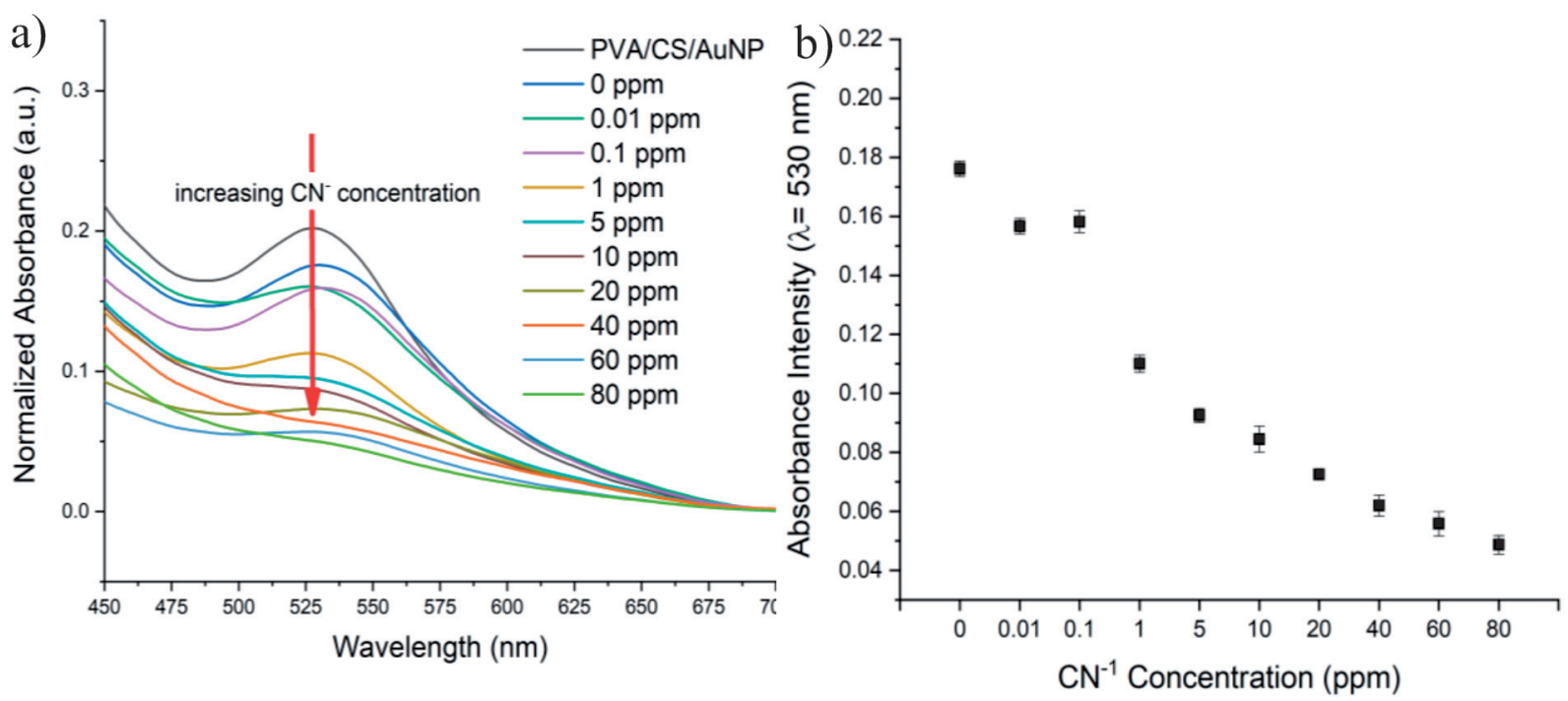

c)

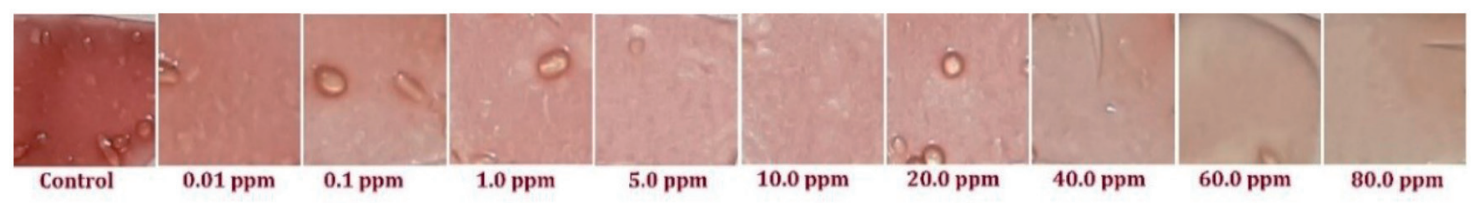

Fig. 5. a) UV-Vis Spectra of the PVA/CS/AuNP Applied with Distilled Water (0 ppm) and Water with Varied $\mathrm{CN}^{-}$concentration $(0.01-80 \mathrm{ppm}), \mathrm{b})$ the Corresponding Line Graph of the Absorbance Intensity, and c) Magnified Photograph of PVA/CS/AuNP with Varied $\mathrm{CN}^{-}$Concentration.
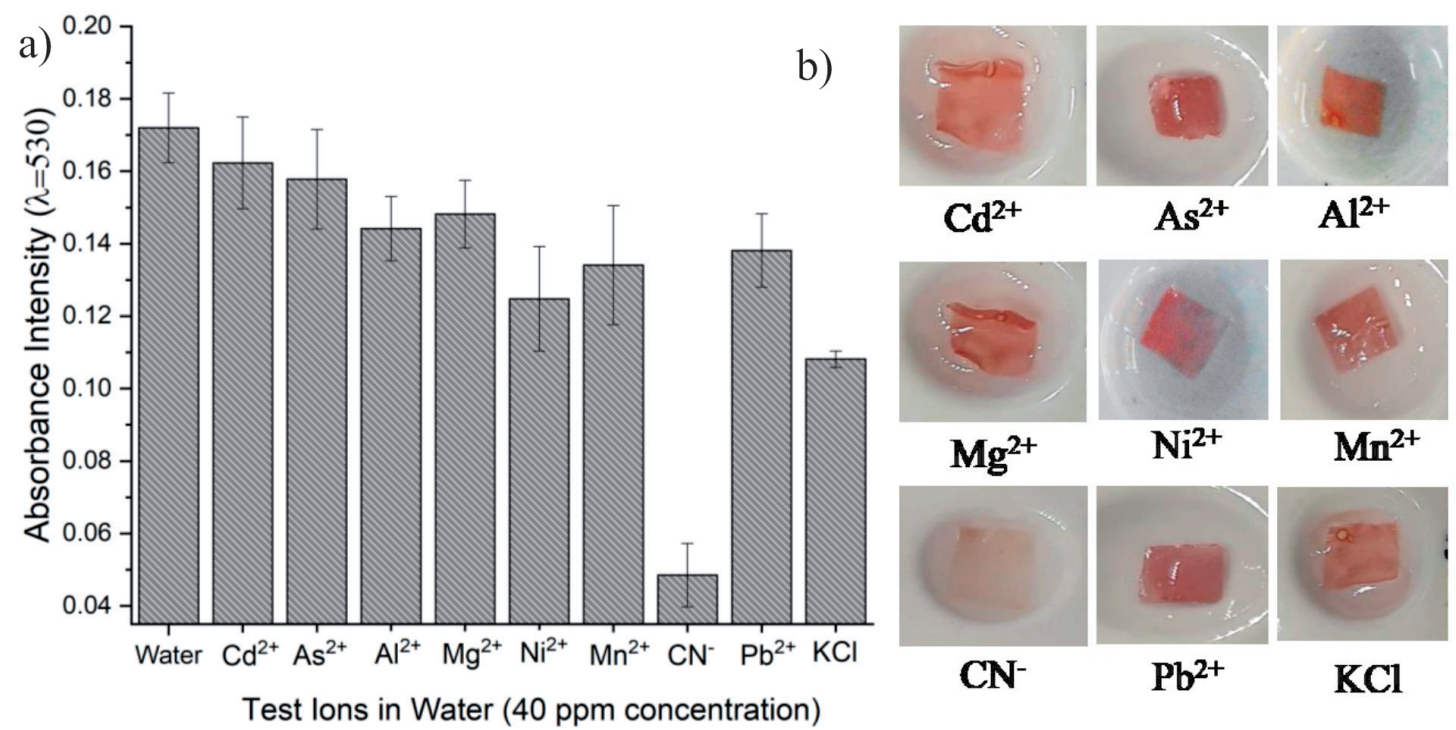

c)
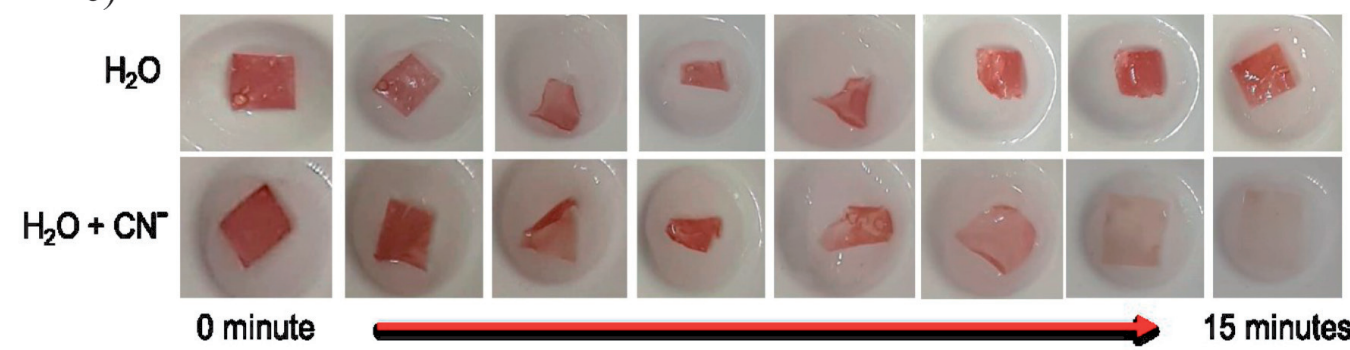

Fig. 6. a) Bar Graph of the Absorbance Intensity of the PVA/CS/AuNP Sensor after Addition of Water Samples with Various Metal Ions (at 40 ppm Concentration) and b) its Corresponding Photograph and c) Images of the PVA/CS/AuNP Sensor in the Presence of Water and Water with $\mathrm{CN}^{-}(40 \mathrm{ppm})$ after 15 minutes of Exposure. 
change was visually appreciable, even up to $0.1-1 \mathrm{ppm}$ of cyanide in water.

The developed PVA/CS/AuNP sensor's selectivity towards $\mathrm{CN}^{-}$against other metal ions was conducted by evaluating the decrease of absorbance at $\lambda=530$ $\mathrm{nm}$. Interestingly, a drastic decrease in the absorbance intensity was observed on the sensor after the addition of water samples with $\mathrm{CN}^{-}$content (Fig. 6a). Furthermore, no dramatic colorimetric change was observed on the samples after the addition of water samples containing the other interfering metal ions. This suggests that the proposed PVA/CS/AuNP colorimetric sensor shown a good selectivity towards $\mathrm{CN}^{-}$. To confirm that the sensor is indeed selective to $\mathrm{CN}^{-}$and not with $\mathrm{K}^{+}$from $\mathrm{KCN}$ used as the cyanide source in this study, the sensor was tested with another potassium-containing salt, $\mathrm{KCl}$. Results revealed that the sensor did not change in color in $\mathrm{KCl}$, confirming that the colorimetric change was due to cyanide (Fig. 6b).

Notably, the composite film manifested a change in size and shape in the sensing process, as seen in Fig. 6c). After about 10 minutes of exposure to the water sample, the sensor shrunk and eventually manifested a volume expansion afterward. The sensor stabilized at about 15 minutes and returned to its original size after drying. This change in shape might indicate the permeation of water and cyanide ions on the polymer matrices and the dissolution of gold nanoparticles on the composite matrix. Certainly, PVA and chitosan are both hydrophilic polymers that may easily facilitate permeation from the surrounding water [26]. The sensor's color change was not due to the expansion because of the water permeation since the color of the composite film did not change even after being exposed to water and even after drying, as shown in Fig. 6c).

As mentioned, the change in the color of the PVA/ CS/AuNP composite film might be attributed to the dissolution chemistry of AuNPs in the presence of cyanide, as indicated in Eq. 1 [33]. The gold nanoparticles on the composite reacted with the free cyanide to form a water-soluble $\mathrm{Au}-\mathrm{CN}$ complex. The dissolution of the AuNPs further leads to the disappearance of the PVA/CS/AuNP composite's red color. A similar observation was reported in previous works that investigated the reaction of colloidal gold nanoparticles with cyanide [33-37].

$4 \mathrm{Au}_{(s)}+8 \mathrm{CN}^{-}{ }_{(a q)}+\mathrm{O}_{2}(g)+2 \mathrm{H}_{2} \mathrm{O} \rightarrow 4 \mathrm{Au}(\mathrm{CN})_{2}{ }^{-}+4 \mathrm{OH}^{-}{ }_{(a q)}$

\section{Conclusions}

A composite of PVA/CS was successfully developed using the spin coating technique. Meanwhile, PEI-reduced gold nanoparticles with an average diameter of around $14.32 \pm 3.49 \mathrm{~nm}$ were added to the PVA/CS blend to produce PVA/CS/AuNP composite. UV-Vis spectroscopy and SEM microscopy revealed the successful integration AuNPs on the PVA/CS.
The feasibility of the synthesized PVA/CS/AuNP composite for $\mathrm{CN}^{-}$detection in water was further investigated. It was revealed that the PVA/CS/AuNP composite could potentially detect $\mathrm{CN}^{-}$in water by observing the disappearance of its red color to colorless. This visual observation was supported by the decrease in absorbance intensity even at low cyanide concentrations. The color change was visually recognizable up to $0.1 \mathrm{ppm}$. Moreover, this behavior was observed exclusively for water samples with cyanide, indicating its good selectivity as a colorimetric sensor. The perceived color change was attributed to the dissolution of the AuNP embedded on the $\mathrm{PVA} / \mathrm{CS} / \mathrm{AuNP}$ matrix in the presence of aqueous cyanide. The developed PVA/CS/AuNP can offer an affordable, fast, and environmental-friendly alternative for cyanide detection and monitoring in water, especially in gold mining and processing sites.

\section{Acknowledgments}

The authors would like to acknowledge the Department of Science and Technology (Philippines) and the Commission on Higher Education (Philippines) for the financial assistance of this project.

\section{Conflict of Interest}

The authors declare no conflict of interest.

\section{References}

1. KŁOS-WITKOWSKA A. Enzyme -based fluorescent biosensosrs and their environmental, clinical and industrial applications. Pol. J. Environ. Stud. 24 (1), 19, 2015.

2. KWAANSA-ANSAH E.E., AMENORFE L.P., ARMAH E.F, OPOKU F. Human health risk assessment of cyanide levels in water and tuber crops from Kenyasi, a mining community in the Brong Ahafo Region of Ghana. International Journal of Food Contamination., 4 (1), 11, 2017.

3. JASZCZAK E., POLKOWSKA Z., NARKOWICZ S., AMIEŚNIK J. Cyanides in the environment-analysisproblems and challenges. Environ. Sci. Pollut. Res. Int. 24 (19), 15929, 2017.

4. ZHENG A., DZOMBAK D., LUTHY R., SAWYER B., LAZOUSKAS W., TATA P., DELANEY M., ZILITINKEVITCH L., SEBROSKI J., SWARTLING R., DROP S., FLAHERTY J. Evaluation and testing of analytical methods for cyanide species in municipal and industrial contaminated waters. Environ. Sci. Technol. 37 (1), 107, 2003.

5. MA J., DASGUPTA, P.K. Recent developments in cyanide detection: A review. Anal. Chim. Acta. 673 (2), 117, 2010.

6. PADEN R., ORACION J.P., DE LA ROSA, L., LAVAPIEZ M.A., ALGUNO A., DEOCARIS C., CAPANGPANGAN R. Design and fabrication of a low-cost curcumin-based paper sensor for rapid "naked-eye" cyanide sensing. Materials Today: Proceedings 46 (4), 1711, 2021. 
7. BUDLAYAN ML, ORACION JP, DE LA ROSA L., RODRIGUEZ M.J., PATRICIO J. ARCO S., MANIGO J., AUSTRIA E., ALGUNO A., DEOCARIS C., CAPANGPANGAN R. Gold nanoparticles-decorated paper-based sensor for rapid cyanide detection in water. Advances in Natural Sciences: Nanoscience and Nanotechnology 12, 025007, 2021.

8. MOMENI S., AHMADI R., SAFAVI A., NABIPOUR I., Blue-emitting copper nanoparticles as a fluorescent probe for detection of cyanide ions. Talanta 175, 514, 2017.

9. WEI S., HSU P., LEE Y., LIN Y., HUANG C., Selective Detection of Iodide and Cyanide Anions Using GoldNanoparticle-Based Fluorescent Probes. ACS Applied Materials \& Interfaces 4, 2652, 2012.

10. KRAJCZEWSKI J., KOŁĄTAJ K., KUDELSKI Y., Plasmonic nanoparticles in chemical analysis. RSC Adv. 7, 17559, 2017.

11. RAD A.G., ABBASI H., AFZALI M.H. Gold nanoparticles: synthesizing, characterizing and reviewing novel application in recent years. Physics Procedia 22, 203, 2011.

12. TANG L., LI J. Plasmon-based colorimetric nanosensors for ultrasensitive molecular diagnostics. ACS Sensors 2 (7), 857, 2017.

13. MATOS R.J.R., CHAPARRO C.I.P., SILVA J.C., VALENTE M.A., BORGES J.P., OARES P.I.P. Electrospun composite cellulose acetate/iron oxide nanoparticles nonwoven membranes for magnetic hyperthermia applications. Carbohydrate Polymers 198, 9, 2018.

14. FERHAN A.R., AND KIM D.H. Nanoparticle polymer composites on solid substrates for plasmonic sensing applications. Nanotoday 11 (4), 415, 2016.

15. WANG P., NASIR M.E., KRASAVIN A.V., DICKSON W., JIANG Y., ZAYATS V. Plasmonic Metamaterials for Nanochemistry and Sensing, Acc. Chem. Res. 52 (11) 3018, 2019.

16. PASTORIZA-SANTOS I., KINNEAR C., PÉREZ-JUSTE J., MULVANEY P., LIZ-MARZÁN, L.M. Plasmonic polymer nanocomposites. Nature Reviews Materials 3, 375, 2018.

17. CHEN C., YANG Y., VLAHOVIC B., YAN F. Electrospun polymer nanofibers decorated with noble metal nanoparticles for chemical sensing. Nanoscale Research Letters 12 (451) 2017.

18. ASHASSI-SORKHABI H., KAZEMPOUR A. Chitosan, its derivatives and composites with superior potentials for the corrosion protection of steel alloys: A comprehensive review. Carbohydrate Polymers 237 (1), 116110, 2020.

19. QAMAR S., ASHIQ M., JAHANGEER M., RIASAT A., BILAL M. Chitosan-based hybrid materials as adsorbents for textile dyes - A review. Case Studies in Chemical and Environmental Engineering 2, 100021, 2020.

20. BAKSHI P.S., SELVAKUMAR D., KADIRVELU K., KUMAR N.S. Chitosan as an environment friendly biomaterial - a review on recent modifications and applications. International Journal of Biological Macromolecules 150, 1072, 2020.

21. MOHANDAS A., DEEPTHI S., BISWAS R., JAYAKUMAR R., Chitosan based metallic nanocomposite scaffolds as antimicrobial wound dressings. Bioactive Materials 3 (3), 267, 2018.

22. AHMED T.A., ALJAEID B.M., Preparation, characterization, and potential application of chitosan, chitosan derivatives, and chitosan metal nanoparticles in pharmaceutical drug delivery. Drug Des Devel Ther. 10, 483, 2016.
23. LIU Y., WANG S., LAN W., QIN W., Fabrication and Testing of PVA/Chitosan Bilayer Films for Strawberry Packaging. Coatings 7 (8), 109, 2017.

24. KOUCHAK M., AMERI A., NASERI B., BOLDAJI S.K. Chitosan and polyvinyl alcohol composite films containing nitrofurazone: Preparation and evaluation. Iranian Journal of Basic Medical Sciences 17 (1), 14, 2014.

25. ABDULLAH Z.W., DONG Y., DAVIES I.J., BARBHUIYA S. PVA, PVA Blends, and Their Nanocomposites for Biodegradable Packaging Application. Polymer-Plastics Technology and Engineering 56 (12), 1307, 2017.

26. RAFIQUE A., ZIA K.M., ZUBER M., TABASUM S., REHMAN S. Chitosan functionalized poly(vinyl alcohol) for prospects biomedical and industrial applications: A review. International Journal of Biological Macromolecules 87, 141, 2016

27. CAZÓN P., VÁZQUEZ M., VELAZQUEZ G., Novel composite films based on cellulose reinforced with chitosan and polyvinyl alcohol: Effect on mechanical properties and water vapour permeability. Polymer Testing 69, 536, 2018

28. CUI Z., ZHENG Z., LIN L., SI J., WANG Q., PENG X., CHEN W. Electrospinning and crosslinking of polyvinyl alcohol/chitosan composite nanofiber for transdermal drug delivery, Adv Polym Technol. 37, 1917, 2018.

29. MARTÍNEZ J.C., CHEQUER N.A., GONZÁLEZ J.L., CORDOVA T., Alternative methodology for gold nanoparticles diameter characterization using PCA technique and UV-VIS spectrophotometry, Nanoscience and Nanotechnology 2 (6), 184, 2012.

30. BRUGNEROTTO J. LIZARDI J., GOYCOOLEA F.M., ARGUĖELLES-MONAL W., DESBRIE ÁRES J., RINAUDO, M. An infrared investigation in relation with chitin and chitosan characterization. Polymer 42, 3569, 2001.

31. AWADA H., DANEAULT C. Chemical modification of poly(Vinyl Alcohol) in water. Applied Sciences 5, 840, 2015.

32. KUMIRSKA J., CZERWICKA M., KACZYŃSKI Z., BYCHOWSKA A., BRZOZOWSKI K., THÖMING J., STEPNOWSKI P. Application of spectroscopic methods for structural analysis of chitin and chitosan, Mar. Drugs. 8 (5), 1567, 2010

33. SUHERMAN A.L., ZAMPARDI G., KUSS S., TANNER E.E., AMIN H.M. YOUNG N.P., Compton R.G. Understanding gold nanoparticle dissolution in cyanidecontaining solution via impact-chemistry. Physical Chemistry Chemical Physics 20, 28300, 2018.

34. LOU X., ZHANG Y., QIN J., LI Z. A Highly Sensitive and Selective Fluorescent Probe for Cyanide Based on the Dissolution of Gold Nanoparticles and Its Application in Real Samples. Chemistry A European Journal 17 (35), 9691, 2011.

35. KIM M.H. KIM S., JANG H.H., YI S., SEO S.H., HAN., M.S. A gold nanoparticle-based colorimetric sensing ensemble for the colorimetric detection of cyanide ions in aqueous solution. Tetrahedron Letters 51, 4712, 2010.

36. CHENG C., CHENA H.Y., WU C.S., MEENA J.S., SIMON T., KO F.H., A highly sensitive and selective cyanide detection using a gold nanoparticle-based dual fluorescence-colorimetric sensor with a wide concentration range, Sensors and Actuators B: Chemical 227, 283, 2016.

37. BIRICH A., STOPIC S., FRIEDRICH B. Kinetic investigation and dissolution behavior of cyanide alternative gold leaching reagents. Scientific Reports 9, 7191, 2019. 